\title{
Virilization in a postmenopausal woman due to ovarian stromal hyperthecosis
}

\author{
Joel M. Goldman' and Lakshmi J. Kapadia ${ }^{2}$
}

'Division of Endocrinology and Metabolism, Department of Medicine, Coney Island Hospital and Department of Medicine, State University of New York Health Science Center at Brooklyn, New York and ${ }^{2}$ Department of Pathology, Coney Island Hospital, Brooklyn, New York, USA

\begin{abstract}
Summary: Virilization in women is occasionally caused by ovarian stromal hyperthecosis. Although three cases of post-menopausal women with hyperthecosis have been reported, the history in two of them strongly suggests a premenopausal origin. We describe a 64 year old woman with postmenopausal virilization due to bilateral ovarian stromal hyperthecosis.
\end{abstract}

\section{Introduction}

Ovarian stromal hyperthecosis is an unusual cause of virilization in women. There are only three previously described cases of ovarian hyperthecosis in postmenopausal women $(51-54 \text { years old })^{1-3}$ with hormone measurements in two of them (Tables I and II). ${ }^{2,3}$ We describe a 64 year old postmenopausal woman with virilization and bilateral ovarian stromal hyperthecosis.

\section{Case report}

A 64 year old woman was referred for hirsutism and temporal balding. She noticed progressive hair growth involving her face, shoulders, chest and abdomen for 8 years. Menarche developed at age 11 and her last menstrual period was at age 46. She described normal periods and three normal pregnancies. A recent investigation for Cushing's syndrome was negative.

Physical examination revealed extensive temporal and anterior baldness and increased facial hair on her upper lip, sideburns and chin (Figure 1). She had generalized obesity, a deep voice, cliteromegaly, male habitus and terminal hair over her shoulders, chest and abdomen. Abdominal and pelvic examinations were otherwise normal.

Testosterone levels were 6.7, 5.4 and $5.0 \mathrm{nmol} / 1$ (normal female $0.5-3.0 \mathrm{nmol} / \mathrm{l}$ ). The morning cortisol was $306 \mathrm{nmol} / \mathrm{l}$ (normal $220-690 \mathrm{nmol} / \mathrm{l}$ ) and

Correspondence: J.M. Goldman, M.D., Division of Endocrinology, Brookdale Hospital Medical Center, Brooklyn, NY 11212, USA.

Accepted: 30 August 1990

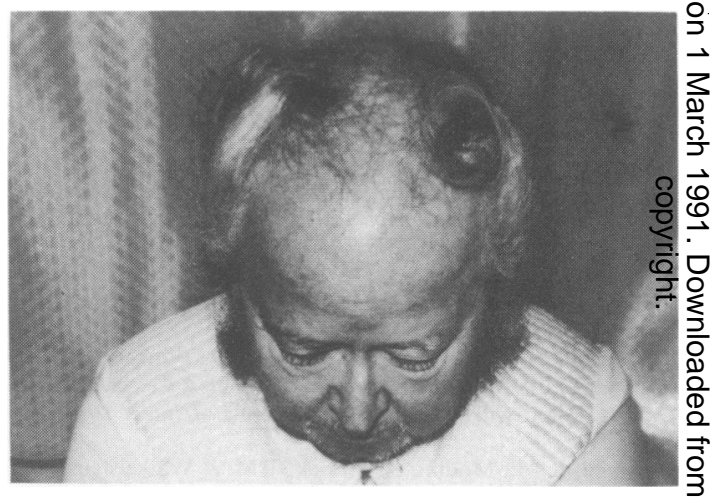

Figure 1 Virilized woman with temporal baldness and facial hair.

after overnight dexamethasone suppression was $69 \mathrm{nmol} / \mathrm{l}$ (normal less than $138 \mathrm{nmol} / \mathrm{l}$ ). Other endocrine results are shown in Table II (Case 4). Thyroid function tests were normal. Ultrasound and computerized tomography examination did not reveal any abnormalities of the ovaries or adrenal glands.

The elevated testosterone levels with normal dehydroepiandrosterone, androstendione, 17- $\odot$ hydroxy and 17-keto steroids and cortisol levels $\mathrm{N}$ suggested an ovarian source for the virilization $\mathrm{N}_{\mathrm{W}}$ (Table II). A bilateral oophorectomy was per- 0 formed which revealed 2.5 and $2.7 \mathrm{~cm}$ ovaries with marked stromal hyperplasia containing luteinized cells (Figure 2). No follicles were seen. At a $\stackrel{?}{\longrightarrow}$ 6-month visit, the patient reported improvement in 0 baldness and decrease in hirsutism. Repeat testosterone level was normal $(2.6 \mathrm{nmol} / \mathrm{l})$. The patient was lost to further follow-up. 
Table I Clinical characteristics of post-menopausal women with hyperthecosis

\begin{tabular}{lcccccc}
\hline Case & Age & Hirsutism & Baldness & Cliteromegaly & $\begin{array}{c}\text { Male } \\
\text { habitus }\end{array}$ & Reference \\
\hline 1 & 54 & + & + & + & + & 1 \\
2 & 53 & + & + & + & + & 2 \\
3 & 51 & + & + & + & $\mathrm{NA}^{*}$ & 3 \\
4 & 64 & + & + & + & + & $\begin{array}{c}\text { Present } \\
\text { case }\end{array}$ \\
\hline
\end{tabular}

*NA - not available.

Table II Hormone levels in post-menopausal women with hyperthecosis

\begin{tabular}{lccccccccc}
\hline Case & $\begin{array}{c}\text { Testosterone } \\
\text { nmol/l }\end{array}$ & $\begin{array}{c}\text { DHEA } \\
\text { nmol/l }\end{array}$ & $\begin{array}{c}\text { DHEA-S } \\
\mu \text { mol/l }\end{array}$ & $\begin{array}{c}\Delta 4 \\
n m o l / l\end{array}$ & $\begin{array}{c}17-O H \\
\mu m o l / d a y\end{array}$ & $\begin{array}{c}17-K S \\
\mu m o l / d a y\end{array}$ & $\begin{array}{c}F S H \\
U / l\end{array}$ & $\begin{array}{c}\text { LH } \\
\text { U/l }\end{array}$ & $\begin{array}{c}\text { Prolactin } \\
\mu g / l\end{array}$ \\
\hline 2 & 13.9 & $\mathrm{NA}^{*}$ & $\mathrm{NA}$ & $\mathrm{NA}$ & 14 & 22 & 78 & 64 & NA \\
3 & 9.8 & $\mathrm{NA}$ & $5.9 * *$ & 9.8 & $\mathrm{NA}$ & $\mathrm{NA}$ & 32 & 38 & 'Normal' \\
4 & 6.7 & 10.4 & 1.2 & 4.5 & 16 & 29 & 36 & 54 & 16 \\
Normal range & $0.5-3.0$ & $5.6-24$ & $0.3-1.7$ & $2.8-10.5$ & $5-25$ & $17-52$ & $>20$ & $>20$ & $<20$ \\
\hline
\end{tabular}

*NA - not available. **Normal range given as 7-54 ${ }^{*} \mathrm{~mol} / \mathrm{l}$. DHEA - dehydroepiandrosterone; DHEA-S dehydroepiandrosterone sulphate; $\Delta 4$-androstenedione; 17-OH - 17-hydroxysteroids; 17-KS - 17-ketosteroids; FSH - follicle stimulating hormone; $\mathbf{L H}$ - luteinizing hormone.

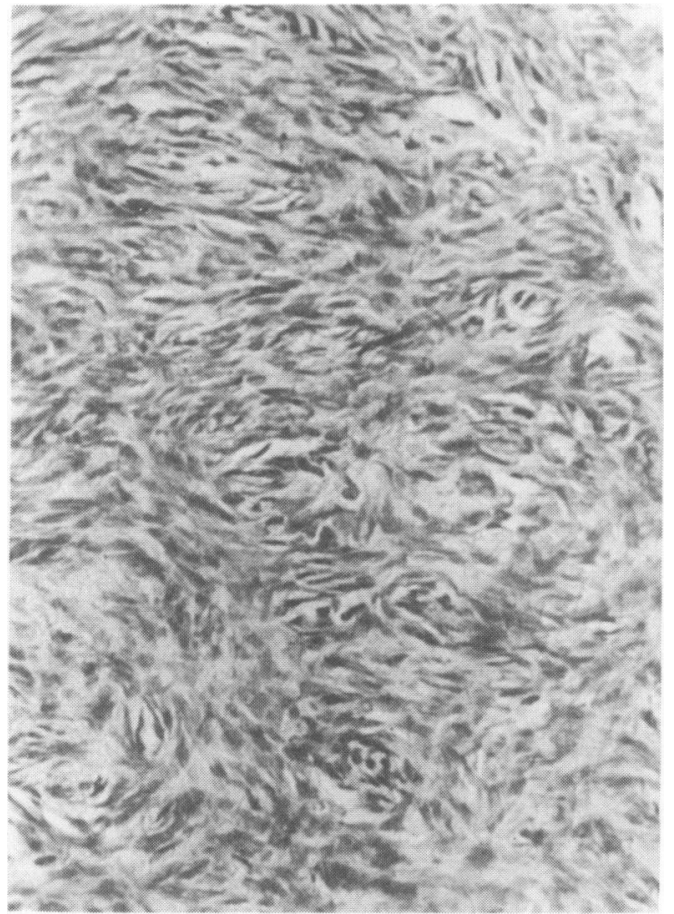

Figure 2 Characteristic ovarian stroma with typical spindle-celled connective tissue cells $(H \& E \times 300)$.

\section{Discussion}

Bilateral ovarian stromal hyperthecosis occasionally causes virilization in premenopausal women. However, a recent review ${ }^{3}$ found only two previously reported cases of stromal hyperthecosis in postmenopausal women ${ }^{1,2}$ and added a third case. ${ }^{3}$ The results of endocrine testing are available for only two of these patients. ${ }^{2,3}$

All three have features in common with our patient (Tables I and II). Testosterone was the only elevated androgen in each case. However, in two cases, ${ }^{1,2}$ the history suggests long-standing virilization probably beginning in the premenopausal period.

The continued secretion of androgens by postmenopausal ovaries has been documented. ${ }^{4,5}$ Gonadal cells are stimulated by high levels of gonadotrophins to produce testosterone and androstenedione. In premenopausal women, androgens are aromatized to oestrogens by granulosa cells. ${ }^{6}$ Since this does not occur to a significant degree in postmenopausal women, androgen secretion predominates. In postmenopausal patients with stromal hyperplasia and hyperthecosis, the significant increase in androgen secretion is associated with increased gonadotrophin secretion (Table II) rather than suppressed gonadotrophin function. In one patient, the gonadotrophins did 
not change after oophorectomy, ${ }^{2}$ in another patient, they appeared to rise after oophorectomy but oestradiol levels were also elevated in this patient before surgery. ${ }^{3}$ The effects of elevated androgen levels on gonadotrophin secretion in women are complex. ${ }^{6}$ Positive feedback, negative feedback and no apparent effect have been described. ${ }^{6}$ It is certainly clear from these 3 patients (Table II) that androgens can be elevated sufficiently to cause profound virilization without decreasing

\section{References}

1. Shippel, S. The ovarian theca cell: part IV - the hyperthecosis syndrome. J Obstet Gynaecol Br Emp 1955, 62: 321-353.

2. Braithwaite, S.S., Erkman-Balis, B. \& Avila, T.D. Postmenopausal virilization due to ovarian stromal hyperthecosis. J Clin Endocrinol Metab 1978, 46: 295-300.

3. Van Heyningen, C., MacFarlane, I.A., Diver, M.J., Muronda, C. \& Tuffnell, D. Virilization due to ovarian hyperthecosis in a postmenopausal woman. Gynecol Endocrinol 1988, 2: 331-338.

4. Chang, R.J. \& Judd, H.L. The ovary after menopause. Clin Obstet Gynecol 1981, 24: 181-191. gonadotrophin levels into the premenopausal range.

Although ovarian hyperthecosis is a recognized cause of premenopausal virilization, it should also $c$ be included as an unusual cause of postmenopausal virilization. The demonstration that this syndrome can develop in the postmenopausal period, as in our patient, strongly suggests that it is a distinct entity and not a late stage of the polycystic ovary syndrome as has been suggested. ${ }^{8}$

5. Cumming, D.C. Menarche, menses and menopause: a brief review. Cleve Clin J Med 1990, 57: 169-175.

6. Cumming, D.C. Androgenesis and androdynamics in normal women. Cleve Clin J Med 1990, 57: 161-166.

7. Barnes, R. \& Rosenfield, R.L. The polycystic ovary syndrome: pathogenesis and treatment. Ann Intern Med 1989, 110: 386-399.

8. Hughesdon, P.E. Morphology and morphogenesis of the Stein-Leventhal ovary and of so-called 'hyperthecosis'. Obstet Gymecol Survey 1982, 37: 59-77. 